\title{
Acinetobacter baumannii: Evolution of Antimicrobial Resistance-Treatment Options
}

\author{
Yohei Doi, MD, PhD ${ }^{1}$ Gerald L. Murray, $\mathrm{PhD}^{2}$ Anton Y. Peleg, MBBS, PhD, MPH, FRACP2,3 \\ ${ }^{1}$ Division of Infectious Diseases, Department of Medicine, University \\ of Pittsburgh School of Medicine, Pittsburgh, Pennsylvania \\ 2 Department of Microbiology, Monash University, Melbourne, \\ Australia \\ ${ }^{3}$ Department of Infectious Diseases, Alfred Hospital, Melbourne, \\ Address for correspondence Yohei Doi, MD, PhD, Division of \\ Infectious Diseases, Department of Medicine, University of Pittsburgh \\ School of Medicine, S829 Scaife Hall, 3550 Terrace Street, Pittsburgh, \\ PA 15261 (e-mail: yod4@pitt.edu).
} Australia

Semin Respir Crit Care Med 2015;36:85-98.

\begin{abstract}
The first decade of the 20th century witnessed a surge in the incidence of infections due to several highly antimicrobial-resistant bacteria in hospitals worldwide. Acinetobacter baumannii is one such organism that turned from an occasional respiratory pathogen into a major nosocomial pathogen. An increasing number of $A$. baumannii genome sequences have broadened our understanding of the genetic makeup of these bacteria and highlighted the extent of horizontal transfer of DNA. Animal models of disease combined with bacterial mutagenesis have provided some valuable insights into mechanisms of $A$. baumannii pathogenesis. Bacterial factors known to be important for disease include outer membrane porins, surface structures including capsule and lipopolysaccharide, enzymes such as phospholipase D, iron acquisition systems, and regulatory proteins. $A$. baumannii has a propensity to accumulate resistance to various groups of antimicrobial agents. In particular, carbapenem resistance has become commonplace, accounting for the majority of $A$. baumannii strains in many hospitals today. Carbapenem-resistant strains are often resistant to all other routinely tested

Keywords

- Acinetobacter baumannii

- virulence

- MDR

- polymyxin agents. Treatment of carbapenem-resistant $A$. baumannii infection therefore involves the use of combinations of last resort agents such as colistin and tigecycline, but the efficacy and safety of these approaches are yet to be defined. Antimicrobial-resistant $A$. baumannii has high potential to spread among ill patients in intensive care units. Early recognition and timely implementation of appropriate infection control measures is crucial in preventing outbreaks.
\end{abstract}

Acinetobacter species comprise a group of genetically related non-lactose-fermenting, oxidase-negative gram-negative coccobacilli. Among them, Acinetobacter baumannii is the most clinically significant Acinetobacter species that is implicated in nosocomial infections; however, Acinetobacter pittii and Acinetobacter nosocomialis are also increasingly recognized in these infections. A. baumannii is intrinsically resistant to several classes of antimicrobial agents and also readily acquires resistance to other classes of agents. It is also extremely resistant to desiccation and may survive on inanimate surfaces for months. These traits make it particularly successful in the hospital environment and have contributed to the spread of multidrug-resistant (MDR) A. baumannii clones worldwide. Infections due to MDR A. baumannii, in particular carbapenem-resistant strains, have been associated with substantial mortality and hospital costs. ${ }^{1,2}$

\section{Classification, Epidemiology, and Clinical Relevance}

There are now more than 20 Acinetobacter species that have been identified, with $A$. baumannii being the most commonly
Issue Theme Antimicrobial Resistance: Management of Superbugs; Guest Editor, David L. Paterson, MBBS, PhD, FRACP, FRCPA
Copyright (c) 2015 by Thieme Medical Publishers, Inc., 333 Seventh Avenue, New York, NY 10001, USA. Tel: +1(212) 584-4662.
DOI http://dx.doi.org/ 10.1055/s-0034-1398388. ISSN $1069-3424$. 
encountered in a clinical setting. ${ }^{3,4}$ In addition, $A$. nosocomialis (genomospecies 13TU) and A. pittii (genomospecies 3) are increasingly implicated in hospital-acquired and healthcare-associated infections. ${ }^{5}$ In contrast, Acinetobacter calcoaceticus is an environmental pathogen of little clinical significance. These four species are biochemically indistinguishable and often lumped together as "Acinetobacter baumannii complex," "Acinetobacter-baumannii/calcoaceticus," or simply "Acinetobacter baumannii" in clinical practice. A. baumannii has been associated with a higher degree of antimicrobial resistance and higher mortality among patients compared with these related non-baumannii species. ${ }^{5}$

A. baumannii can cause a wide variety of infections. The majority of the cases involve the respiratory tract, but bacteremia, meningitis, and wound infection may also occur, the last of which was prominently observed in the context of warrelated trauma. ${ }^{3}$ A survey in U.S. hospitals showed that the majority of the isolates (57.6\%) were from the respiratory tract, followed by bloodstream (23.9\%) and skin or wound (9.1\%) in 2010..$^{6}$ Acinetobacter species ranked fifth as the causative organism of ventilator-associated pneumonia (6.6\%) and thirteenth as the cause of central line-associated bloodstream infection (2.1\%). ${ }^{7}$

Acinetobacter used to be susceptible to most antimicrobial agents ranging from ampicillin to nalidixic acid up to the early $1970 s^{8}$ However, rates of resistance increased for many classes in the 1980s, and by early 1990s reports on imipenem-resistant isolates appeared. This was a concerning development because it took away the most reliable treatment option for Acinetobacter infections. In 2010, 44.7 and $49.0 \%$ of isolates were resistant to imipenem and meropenem, respectively, in the earlier-mentioned U.S. survey. ${ }^{6}$ A. baumannii isolates that are resistant to carbapenems are always resistant to penicillins and cephalosporins and often to aminoglycosides and fluoroquinolones as well. Most isolates remain susceptible to colistin, but again colistin-resistant isolates are increasingly reported, especially following treatment of infection by carbapenem-resistant isolates with this agent. ${ }^{9}$

The worldwide spread of MDR A. baumannii, in particular carbapenem-resistant isolates, is understood as a largely clonal phenomenon. ${ }^{10}$ In a survey of nearly 500 carbapenem-non-susceptible isolates collected globally in the mid2000s, about half of them originating from various continents belonged to European Clone II (also called Worldwide Clone 2) by molecular typing. ${ }^{11}$ Other Worldwide Clones (WW1 and WW2 through WW8) have also wide distribution and thus contribute to the international spread of carbapenem-resistant $A$. baumannii.

The risk factors for acquiring MDR and carbapenem-resistant isolates include recent exposure to antimicrobial agents (in particular carbapenems), the presence of central venous catheters or urinary catheters, severity of illness, duration of hospital stay, location in an intensive care unit (ICU), larger hospital size, and recent surgery. ${ }^{12-15}$ Mortality from invasive A. baumannii infection is high, especially when the isolate is resistant to carbapenems. Crude mortality for carbapenemresistant $A$. baumannii infections ranges from 16 to $76 \%{ }^{16}$ Risk factors for mortality among patients with carbapenem- resistant $A$. baumannii bloodstream infections include the severity of illness, underlying malignancy, history of transplant, higher age, septic shock, concurrent pneumonia, inappropriate antimicrobial therapy, prolonged ICU stay, and renal failure, among others. ${ }^{17-22}$ High mortality rates observed in patients with carbapenem-resistant $A$. baumannii infection are attributed to greater severity of illness and higher risk of receiving early inappropriate antimicrobial therapy. ${ }^{16}$

\section{A. baumannii Virulence Mechanisms}

Despite the increasing importance of MDR A. baumannii disease, our understanding of mechanisms of pathogenesis remains in its infancy. An increasing number of $A$. baumannii genome sequences have broadened our understanding of the genetic makeup of these bacteria and highlighted the extent of horizontal transfer of DNA. ${ }^{23}$ Animal models of disease (both mammalian and invertebrate) combined with bacterial mutagenesis have provided some valuable insights into mechanisms of A. baumannii pathogenesis. Bacterial factors known to be important for disease are presented in - Table 1; these include outer membrane porins, ${ }^{24-26}$ surface structures including capsule ${ }^{27}$ and lipopolysaccharide, ${ }^{28}$ enzymes such as phospholipase $\mathrm{D},{ }^{29}$ iron acquisition systems, ${ }^{30}$ and regulatory proteins. ${ }^{31}$ The following paragraphs will discuss different stages of the infection process and highlight known virulence factors.

Transmission is the initial step in disease. The propensity for biofilm formation is likely to contribute to prolonged survival of $A$. baumannii on abiotic surfaces, leading to transmission. However, a definitive link between outbreak strains, biofilm formation, and adherence to host cells has not been established. ${ }^{32} A$. baumannii biofilm formation on indwelling devices, such as urinary catheters, central venous catheters, and endotracheal tubes, may seed infection. ${ }^{33}$ Notably, bacteria in biofilms are more resistant to desiccation, immune system clearance, antibiotics, and other antibacterial agents. ${ }^{34,35}$ Established factors that contribute to A. baumannii biofilm formation include pili, outer membrane proteins, and extracellular polysaccharide ( - Table $\mathbf{1}$ ).

Binding to host structures is necessary for colonization. $A$. baumannii has been shown to adhere to a range of host cells in vitro including laryngeal, bronchial, and alveolar respiratory epithelial cells. ${ }^{24,36,37}$ In vivo, such binding may be the first stage in the development of pneumonia. The molecular basis for such interactions is being unraveled; adhesins that mediate binding to host cells include OmpA, Bap, and Omp33$36 .{ }^{26}$ While specific host ligands for these interactions have not been thoroughly investigated, cellular fibronectin is one adhesin target ( - Table $\mathbf{1}$ ). ${ }^{38}$ The autotransporter Ata has also been found to adhere to numerous host extracellular matrix proteins, which may also facilitate tissue colonization. ${ }^{39}$

Binding to host cells is followed by cellular damage and $A$. baumannii invasion. While not considered a classical intracellular pathogen, invasion may be a way to avoid immune recognition. Multiple factors including OmpA, Omp33-36, and phospholipase $\mathrm{D}$ are necessary for $A$. baumannii cell 
Table 1 Acinetobacter baumannii virulence functions and associated bacterial factors

\begin{tabular}{|c|c|c|c|c|}
\hline Virulence function & Related protein(s) & $\begin{array}{l}\text { Protein function/ } \\
\text { description }\end{array}$ & $\begin{array}{l}\text { Mutant attenuated in disease } \\
\text { model }^{\mathrm{a}}\end{array}$ & Reference \\
\hline \multirow[t]{11}{*}{ Biofilm formation } & Abal & $\begin{array}{l}\text { Autoinducer synthase (quo- } \\
\text { rum sensing) }\end{array}$ & NT & 153 \\
\hline & Ata & Autotransporter & Mouse septicemia & 39 \\
\hline & Bap & $\begin{array}{l}\text { Biofilm maturation and } \\
\text { maintenance }\end{array}$ & NT & 154,155 \\
\hline & $\mathrm{BfmS/R}$ & Two-component regulator & NT & 47,156 \\
\hline & CsuA/B ABCDE & $\begin{array}{l}\text { Pilus production (usher } \\
\text { chaperone) }\end{array}$ & NT & 157 \\
\hline & Gacs & $\begin{array}{l}\text { Sensor of two-component } \\
\text { regulator }\end{array}$ & Mouse septicemia & 31 \\
\hline & $\mathrm{H}-\mathrm{NS}$ & $\begin{array}{l}\text { Transcriptional regulator } \\
\text { (suppressor) }\end{array}$ & C. elegans & 48 \\
\hline & OmpA & Outer membrane porin & Mouse pneumonia & 24,37 \\
\hline & PgaABC & $\begin{array}{l}\text { Production of poly- } \beta-1,6-N- \\
\text { acetylglucosamine (PNAG) }\end{array}$ & NT & 158 \\
\hline & PglC & $\begin{array}{l}\text { Protein glycosylation, cap- } \\
\text { sule production }\end{array}$ & Mouse septicemia & 159 \\
\hline & PglL & Protein O-glycosylation & Mouse septicemia & 160 \\
\hline $\begin{array}{l}\text { Adhesion to extra- } \\
\text { cellular matrix }\end{array}$ & Ata & Autotransporter & See above & 39 \\
\hline \multirow[t]{4}{*}{$\begin{array}{l}\text { Adhesion to host } \\
\text { cells }\end{array}$} & Bap & $\begin{array}{l}\text { Biofilm maturation and } \\
\text { maintenance }\end{array}$ & NT & 154,155 \\
\hline & $\mathrm{BfmS/R}$ & Two-component regulator & NT & 47,156 \\
\hline & H-NS & $\begin{array}{l}\text { Transcriptional regulator } \\
\text { (repressor) }\end{array}$ & See above & 48 \\
\hline & OmpA & Outer membrane porin & See above & 37 \\
\hline \multirow[t]{4}{*}{$\begin{array}{l}\text { Invasion and intra- } \\
\text { cellular survival }\end{array}$} & BasD, BauA & $\begin{array}{l}\text { Siderophore synthesis (iron } \\
\text { acquisition) }\end{array}$ & Mouse septicemia & 30 \\
\hline & Omp33-36 & $\begin{array}{l}\text { Outer membrane porin } \\
\text { (perturbation of autophagy) }\end{array}$ & Mouse septicemia & 25,26 \\
\hline & OmpA & Outer membrane porin & See above & 24 \\
\hline & Pld & Phospholipase D & Mouse septicemia & 29 \\
\hline \multirow{4}{*}{$\begin{array}{l}\text { Cytotoxicity/induc- } \\
\text { tion of apoptosis/ } \\
\text { cellular necrosis }\end{array}$} & BasD, BauA & $\begin{array}{l}\text { Siderophore synthesis (iron } \\
\text { acquisition) }\end{array}$ & Mouse septicemia & 30 \\
\hline & OmpA & Outer membrane porin & See above & $37,40,41$ \\
\hline & Omp33-36 & Outer membrane porin & See above & 26 \\
\hline & PaaE & $\begin{array}{l}\text { Production of toxic epoxide } \\
\text { compounds }\end{array}$ & Mouse septicemia & 31 \\
\hline \multirow[t]{6}{*}{ Serum resistance } & $\mathrm{BfmS/R}$ & Two-component regulator & NT & 47 \\
\hline & LpsB & LPS synthesis & Rat soft tissue & 28 \\
\hline & OmpA & Outer membrane porin & See above & 44 \\
\hline & PglC & $\begin{array}{l}\text { Protein O-glycosylation and } \\
\text { capsule production }\end{array}$ & See above & 159 \\
\hline & Pld & Phospholipase D & See above & 29 \\
\hline & Ptk, EpsA & Capsule production & Rat soft tissue & 27 \\
\hline
\end{tabular}

Abbreviation: NT, not tested.

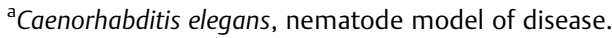


invasion. ${ }^{24,25,29,37}$ Once inside host cells, BasD and BauA (involved in the synthesis and transport of small, iron chelating molecules called siderophores) are required for survival. ${ }^{30}$ Omp33-36 also interferes with autophagy, which may promote survival of $A$. baumannii in host cells. ${ }^{25}$ It has been shown that cellular damage can be mediated by A. baumannii outer membrane proteins, more specifically OmpA and Omp33-36, which both contribute to apoptosis. ${ }^{25,37,40,41}$ These proteins have also been shown to play a role in virulence in mammalian infection models. ${ }^{24,26}$

Bloodstream infection is a common complication of $A$. baumannii infection; accordingly, most clinical isolates are resistant to the bactericidal activity of serum complement. ${ }^{42}$ Complement evasion strategies may prevent direct lysis of bacteria by the membrane attack complex, reduce opsonization for phagocytes, and blunt production of complement inflammatory mediators. As with other pathogens, A. baumannii serum resistance is multifactorial, conferred in part by lipopolysaccharide and capsule. ${ }^{27,28,42}$ LPS is also necessary for defense against antimicrobial peptides such as LL-37. ${ }^{43}$ Many bacteria also evade complement activity by binding to soluble mediators of complement regulation such as factor $\mathrm{H}$ of the alternative pathway. One study indicated that $A$. baumannii co-opts factor $\mathrm{H}$ via several proteins including OmpA. ${ }^{44}$ Consistent with this finding, mice infected with an OmpA mutant had 1,000-fold lower burdens of bacteria in the blood consistent with a role in serum resistance. ${ }^{24}$ However, a second study found no evidence for factor $\mathrm{H}$ binding on the surface of clinical isolates of $A$. baumannii. ${ }^{45}$ Proteases can also mediate immune evasion by degrading bound complement molecules and antibodies. Consistent with this, the secreted protease dubbed PKF also contributes to serum resistance. $^{46}$

Regulation of the expression of virulence traits is essential for pathogens. Several regulators of A. baumannii virulence have been identified. GacSA is a two-component global virulence regulator essential for disease. ${ }^{31}$ Mutation of the sensor kinase gene gacS altered the expression of genes involved in pili synthesis, motility, and biofilm formation; there was a consistent defect in the corresponding in vitro phenotypes, in addition to reduced growth in human serum. GacSA was also found to regulate components of a pathway for aromatic amino acid metabolism; mutation of paaE from this system confirmed a role in virulence. The BfmRS twocomponent regulator also controls multiple phenotypes, including biofilm formation, adherence to host cells, and resistance to human serum. ${ }^{47}$ The bacterial histone-like nucleoid structuring protein (H-NS) may have a role in regulating hydrophobicity, biofilm formation, adherence to host alveolar macrophages, and motility in A. baumannii. An hns mutant had significantly increased virulence toward the nematode Caenorhabditis elegans, potentially a result of upregulation of the type VI secretion system and a known virulence factor, the ata autotransporter. ${ }^{48}$ Further study of these and other virulence regulators will facilitate identification of novel virulence factors of $A$. baumannii, thereby broadening our understanding of host-pathogen interactions.
It is likely that many mechanisms of disease pathogenesis remain undiscovered, and are sufficiently novel to evade identification by "genome browsing." Broad-based methodology for identification of factors by screening of transposon mutant libraries has been successfully applied in various model systems. A screening of 1,324 transposon mutants for virulence against the nematode $C$. elegans and amoeba Dictyostelium discoideum identified 14 genes that may have a role in virulence (absent in the environmental organism Acinetobacter baylyi). ${ }^{23}$ However, the role of these factors in disease has not been verified by complementation with a functional copy of the gene, nor confirmed in a mammalian host. In vivo analysis of a library of 150,000 unique transposon insertion mutants in a high throughput sequencing strategy found 157 genes necessary for persistence in the mouse lung, including previously identified virulence factors OmpA, LPS, BfmRS, and GacA. ${ }^{49}$ Several mutants were individually analyzed and found to be attenuated in the mouse. Further validation of these results through mutagenesis and complementation may reveal novel virulence mechanisms. Given the lack of new antimicrobials in the pipeline for problematic MDR organisms, virulence factors constitute novel therapeutic targets for rational drug design.

\section{Host Immune Responses}

Neutrophils play an important role in the immune response to $A$. baumannii infection. In mice, neutrophils are rapidly recruited to lungs during infection, and after clearance of bacteria, neutrophil numbers return to normal. ${ }^{50}$ Neutrophil depletion exacerbated disease in systemic and pulmonary models of mouse infection. ${ }^{50,51}$ In the study of Breslow et $\mathrm{al}^{, 51}$ increased burdens of bacteria in the lung, decreased production of proinflammatory cytokines, and enhanced bacterial dissemination to extrapulmonary sites were observed. Macrophages also appear to play a significant, but less important, role in the early phase of lung infection through phagocytosis, release of cytokines, and neutrophil recruitment. $^{52}$

Toll-like receptor 4 (TLR4) and CD14 are important for the detection of $A$. baumannii LPS; mice lacking these receptors were more susceptible to pulmonary disease and exhibited delayed lung inflammation and reduced cytokine production. ${ }^{53}$ In vitro, TLR4-deficient murine bone-marrow-derived macrophages had reduced ability to kill $A$. baumannii. ${ }^{54} A$. baumannii LPS is also a potent stimulator of human THP-1 monocytes in vitro; signaling via TLR4, LPS stimulated the production of IL- 8 and TNF- $\alpha$. TLR2 may also play a role in response to whole $A$. baumannii cells. ${ }^{55}$ Recently, it has been shown that during the intracellular phase of $A$. baumannii infection, the intracellular pattern recognition receptors Nod1 and Nod2 are stimulated in airway epithelial cells, resulting in the production of cytokines, chemokines, and $\beta$-defensin 2 . $^{56}$

It is clear that immunity to A. baumannii can be conferred by antibodies. Vaccination with an outer membrane complex of proteins and LPS protected mice against challenge, and animals that received a passive infusion of immune serum 
were also protected against disease. ${ }^{57}$ Although the specific antigens responsible for protection were not identified in this study, a survey of immunostimulatory antigens of $A$. baumannii in sera from 50 patients identified six dominant outer membrane proteins that were immunogenic. ${ }^{58}$ In another study, vaccination with OmpA alone protected a proportion of animals from infection, as did a passive infusion of vaccinate sera, and immune sera increased opsonophagocytosis of $A$. baumannii. ${ }^{59}$ In addition to furthering knowledge of mechanisms of immunity toward A. baumannii, these studies show the promise of active vaccination and passive immunotherapy (through infusion of antibodies) against A. baumannii disease.

\section{Antimicrobial Resistance Mechanisms}

Owing to a propensity for acquisition of foreign DNA, A. baumannii can assemble and modulate a host of antimicrobial resistance mechanisms to survive the selective pressure they encounter, providing them with a strong ecological advantage in the hospital environment (-Table 2 ).

\section{Cephalosporins}

A majority of A. baumannii clinical isolates are now resistant to cephalosporins, including third-generation (e.g., ceftazidime) and fourth-generation (e.g., cefepime) agents. A. baumannii naturally produces AmpC $\beta$-lactamase (called ADC [Acinetobacter-derived cephalosporinase]). ${ }^{60,61}$ Unlike other gramnegative organisms where production of AmpC can be induced or permanently de-repressed, the ADC $\beta$-lactamase in $A$. baumannii is not considered inducible. ${ }^{61}$ However, expression of ADC $\beta$-lactamase is enhanced when certain insertion sequences are acquired upstream of the gene and provides a strong promoter activity, leading to a clinically relevant level of resistance. ${ }^{62,63}$ In addition to ADC $\beta$-lactamase, A. baumannii may also produce extended-spectrum $\beta$-lactamase (ESBL), which also leads to cephalosporin resistance. ${ }^{64-67}$

\section{Carbapenems}

The most significant mechanism of carbapenem resistance in A. baumannii is the production of carbapenemases, which can

Table 2 Mechanisms of antimicrobial resistance in Acinetobacter baumannii

\begin{tabular}{|c|c|c|c|}
\hline Agents & Related protein(s) & Protein function/description & Reference \\
\hline \multirow[t]{5}{*}{ Cephalosporins } & $\mathrm{ADC}$ & Intrinsic AmpC $\beta$-lactamase & 60,61 \\
\hline & CTX-M & Acquired extended-spectrum $\beta$-lactamase & $64-67$ \\
\hline & PER & & \\
\hline & GES & & \\
\hline & VEB & & \\
\hline \multirow[t]{4}{*}{ Carbapenems } & OXA-51-group & Intrinsic serine carbapenemase & 68,69 \\
\hline & OXA-23/40/58/143/235-group & Acquired serine carbapenemase & 70,71 \\
\hline & NDM & Acquired metallo- $\beta$-lactamase & 72,73 \\
\hline & KPC & Acquired serine carbapenemase & 77 \\
\hline \multirow[t]{2}{*}{ Sulbactam } & TEM & Acquired serine $\beta$-lactamase & 80 \\
\hline & PBP2 & Penicillin-binding protein (reduced expression) & 79 \\
\hline \multirow[t]{3}{*}{ Rifampin } & RpoB & RNA polymerase $\beta$-subunit (amino acid changes) & 81 \\
\hline & Unknown & Efflux pump & 81 \\
\hline & Arr & ADP-ribosyltransferase & 82 \\
\hline \multirow[t]{5}{*}{ Aminoglycosides } & AAC & Aminoglycoside acetyltransferase & $83-85$ \\
\hline & $\mathrm{APH}$ & Aminoglycoside phosphotransferase & \\
\hline & AAD & Aminoglycoside adenylyltransferase & \\
\hline & $\operatorname{ArmA}$ & 16S ribosomal RNA methyltransferase & $86-88$ \\
\hline & RmtB & 16S ribosomal RNA methyltransferase & 161 \\
\hline \multirow[t]{3}{*}{ Fluoroquinolones } & GyrA & DNA gyrase (amino acid changes) & 67 \\
\hline & ParC & DNA topoisomerase IV (amino acid changes) & \\
\hline & AdeFGH & RND efflux pump & 89 \\
\hline \multirow[t]{2}{*}{ Colistin } & PmrCAB & Two-component regulatory system (amino acid changes) & $90-92$ \\
\hline & $\mathrm{LpxA} / \mathrm{C} / \mathrm{D}$ & Lipopolysaccharide (complete loss) & 93 \\
\hline \multirow[t]{2}{*}{ Tetracyclines } & $\operatorname{Tet}(30) /(39) /(A) /(B)$ & MFS efflux pump & 162 \\
\hline & AdeABC/FGH/IJK & RND efflux pump & 95 \\
\hline
\end{tabular}


be either intrinsic or acquired. A. baumannii naturally produces chromosomally encoded OXA-51-group carbapenemase at a low level, and acquisition of a stronger promoter by transposition of an insertion sequence, analogous to the case with $A D C$, upstream of the OXA-51-group gene may lead to elevation of carbapenem MICs. ${ }^{68,69} A$. baumannii also becomes resistant to carbapenems when they acquire certain OXA-group $\beta$-lactamase genes on plasmids. There are five major groups of acquired OXA-group carbapenemases in $A$. baumannii, including OXA-23, -40, -58, -143, and -235 groups. ${ }^{70}$ Among these, OXA-23 group is the most prevalent, often produced by Worldwide Clone 2 isolates. $^{71}$

Recently, non-OXA group carbapenemases that have spread in Enterobacteriaceae are also being acquired by $A$. baumannii. The most concerning among these is the metallo$\beta$-lactamase NDM-1. Carbapenem-resistant A. baumannii producing NDM-1 has been identified worldwide since $2011 .^{72,73}$ Other acquired metallo- $\beta$-lactamases have also been reported on rare occasions. ${ }^{74-76}$ Finally, A. baumannii producing KPC-group carbapenemase has been reported in Puerto Rico, but there is no evidence that it has spread beyond this island. ${ }^{77}$

\section{Sulbactam}

Sulbactam is a $\beta$-lactamase inhibitor which is usually combined with ampicillin or cefoperazone to mitigate their hydrolysis by class $A \quad \beta$-lactamases, but it also has intrinsic activity against Acinetobacter species including A. baumannii, presumably by binding to penicillin-binding protein PBP2. ${ }^{78}$ Reduced expression of PBP2 and production of TEM- $1 \beta$ lactamase have been associated with resistance to sulbactam in A. baumannii. $^{79,80}$

\section{Rifampin}

Rifampin exerts its activity by binding to the bacterial RNA polymerase and inhibiting transcription initiation. The major mechanism underlying rifampin resistance is amino acid substitutions in the $\beta$-subunit of this target protein. ${ }^{81}$ Since this can occur through a single mutation to the $r p o B$ gene encoding this subunit, monotherapy with rifampin is contraindicated in any bacteria, and A. baumannii is no exception. Besides this mechanism, enzymatic modification of rifampin and active efflux have also been associated with resistance to rifampin. ${ }^{81,82}$

\section{Aminoglycosides}

Aminoglycosides bind to the $16 \mathrm{~S}$ ribosomal RNA of the $30 \mathrm{~S}$ ribosomal subunit and inhibits protein synthesis. A. baumannii produces various aminoglycoside-modifying enzymes to acquire aminoglycoside resistance. ${ }^{83-85}$ Another aminoglycoside resistance mechanism that is emerging is production of 16S ribosomal RNA methyltransferase, especially ArmA. ArmA methylates a guanine residue in the aminoglycosidebinding site (A-site) of 16S rRNA and protects it from binding aminoglycosides. ${ }^{86}$ ArmA-producing $A$. baumannii are highly resistant to gentamicin, tobramycin, and amikacin, and are commonly seen among Worldwide Clone 2 isolates. ${ }^{87,88}$

\section{Fluoroquinolones}

Fluoroquinolones bind to the DNA gyrase and topoisomerase IV and interfere with DNA synthesis leading to cell death. The primary mechanism of resistance to fluoroquinolones is amino acid substitutions in the quinolone resistance determining region of the genes that encode these target proteins. ${ }^{67}$ This mechanism results in high-level fluoroquinolone resistance. In addition, $A$. baumannii may overexpress active efflux pumps to gain moderate level of fluoroquinolone resistance. $^{89}$

\section{Colistin}

Colistin is a cyclic cationic antimicrobial peptide that binds to lipid A to initiate its bactericidal activity. Resistance to colistin arises due to modifications of this target in clinical isolates. The addition of phosphoethanolamine to the hepta-acylated lipid $\mathrm{A}$ is the commonly reported modification associated with colistin resistance. ${ }^{90-92}$ Complete loss of lipopolysaccharide is also proposed as a mechanism leading to colistin resistance, though this phenomenon is mostly observed in laboratory isolates rather than clinical isolates. ${ }^{93}$

\section{Tetracyclines}

Tetracyclines bind to the $30 \mathrm{~S}$ ribosomal subunit for its activity. Resistance develops by active efflux or target protection by production of Tet proteins that bind to the $70 \mathrm{~S}$ ribosome. ${ }^{94}$ Tigecycline was designed to resist the majority of these mechanisms, but is still prone to efflux by Ade-type efflux pumps in $A$. baumannii, especially when these pumps are overexpressed. ${ }^{95}$

\section{Prevention of $\boldsymbol{A}$. baumannii Colonization and Infection}

A. baumannii, in particular carbapenem-resistant or other highly resistant strains, have a propensity to cause outbreaks when they enter the hospital environment. Both antimicrobial and desiccation resistances play an important role in this phenomenon. A. baumannii is highly resistant to desiccation and can survive on inanimate surfaces for at least 1 month. ${ }^{96}$ Environmental sites may be contaminated with MDR A. baumannii in almost half of the hospital rooms accommodating patients with a history of these bacterial infection or colonization. ${ }^{97}$ Therefore, transmission occurs both through direct patient contact and contact with the environment of the patient's room. In one study, the gloves and/or gowns of caregivers were contaminated after $39 \%$ of all encounters with patients colonized with MDR A. baumannii, suggesting that these contact precaution measures are essential in preventing the organism from being transmitted to another patient by healthcare workers. ${ }^{98}$ 
Once an outbreak is identified, the infection control measures require a bundled approach that typically includes implementation of strict contact precaution, educational activities, enhanced terminal cleaning procedures, and investigation of environmental sources. In addition, molecular typing of the relevant $A$. baumannii isolates should be considered to define the extent of the outbreak, using techniques such as pulsed-field gel electrophoresis or multilocus variable number of tandem repeats analysis. As a case in point, an outbreak of extensively drug-resistant $A$. baumannii at an ICU in a Virginia hospital was brought under control after an intervention was implemented consisting of weekly meetings with the unit personnel, reinforcement of contact precautions and hand hygiene, cohorting of infected patients and their nursing and respiratory care staff, daily chlorhexidine bathing, preemptive contact precaution until negative surveillance culture was obtained, and restriction of carbapenem use. $^{99}$

Unlike other MDR organisms such as methicillin-resistant Staphylococcus aureus or vancomycin-resistant enterococci, active surveillance or screening for A. baumannii is not conducted routinely at most institutions because of the low sensitivity of screening, which ranges between 55 and $90 \%$ depending on the methods. ${ }^{100,101}$ Nonetheless, active screening was estimated to reduce $A$. baumannii transmission, infections, and deaths by 48 to $78 \%$ depending on the screening methods and to be cost-effective when the carrier prevalence exceeds $2 \%{ }^{102}$

\section{Treatment Options for $A$. baumannii Infection}

Carbapenems have generally been considered the agents of choice for treatment of infections caused by A. baumannii, owing to their intrinsic activity against this organism and their favorable safety profile. However, the declining susceptibility to carbapenems has forced clinicians and researchers to explore alternative therapeutic approaches. Adding to the challenge is that by the time $A$. baumannii acquires resistance to carbapenems, there are often resistant to all other commonly used agents as well. Strains that are extensively drug resistant (XDR, resistant to all classes except up to two) usually remain susceptible to polymyxins (colistin or polymyxin B) and tigecycline. Therefore, regimens will include at least one of these two classes of agents with or without a second agent.

\section{Polymyxins}

Polymyxins are amphipathic polypeptides that interact with lipid A of the gram-negative bacterial outer membrane and cause rapid cell death in a concentration-dependent manner. Of the two polymyxins, colistin is administered intravenously as its inactive prodrug colistin methanesulfonate (CMS), whereas polymyxin B is administered as an active drug. CMS is the more commonly used polymyxin formulation worldwide, and thus has more cumulative clinical experience accompanying it. Polymyxin resistance remains relatively rare in A. baumannii, though it can develop after treatment with CMS. ${ }^{6,9,103}$ The killing activity of colistin is best correlated with the free area under the curve/MIC (fAUC/MIC). ${ }^{104}$ In time-kill studies, colistin exerts a rapid bactericidal effect, but regrowth can occur at colistin concentrations exceeding the MICs. ${ }^{105}$ It has been hypothesized that subpopulations with increased tolerance to colistin concentrations higher than the MICs exist in clinical strains and that killing of the susceptible population results in the amplification of these hetero-resistant subpopulations. ${ }^{106}$ Also, because CMS has to be converted to colistin in the plasma, patients are exposed to suboptimal concentrations of colistin for 2 to 3 days before the concentrations reach the steady state with an average maximum concentration of approximately $2.3 \mu \mathrm{g} / \mathrm{mL}$, with large individual variations. ${ }^{107,108}$ To mitigate these concerns of inadequate plasma levels of colistin and potential for development of resistance, the use of a loading dose is now advocated for colistin, ${ }^{107,109}$ and combination therapy with a second active agent or an agent that is inactive by itself but demonstrates synergy with colistin is widely adopted. Another implication is that, based on these pharmacokinetic properties, the current susceptibility breakpoint of $2 \mu \mathrm{g} / \mathrm{mL}$, defined by both the Clinical Laboratory Standards Institute (CLSI) and European Committee on Antimicrobial Susceptibility Testing (EUCAST), may not be adequate and a lower breakpoint may be needed. However, nephrotoxicity limits the dosing of intravenous CMS, with approximately $50 \%$ of the patients manifesting variable degrees of nephrotoxicity due to this agent. ${ }^{104}$ This is a reversible process in most instances.

While clinical data regarding the efficacy of intravenous CMS for A. baumannii infection when used alone are scarce, a retrospective study of 35 patients with ventilator-associated pneumonia caused by $A$. baumannii who were treated with either colistin or imipenem according to actual susceptibility has shown comparable clinical cure and in-hospital mortality rates at 57\% each and 62 versus 64\%, respectively, suggesting that colistin may be as efficacious as imipenem when the latter cannot be used due to resistance. ${ }^{110}$ In this study, colistin was dosed at 2.5 to $5 \mathrm{mg} / \mathrm{kg} / \mathrm{d}$ but without a loading dose.

Given the less than ideal pharmacokinetics of colistin and concerns over nephrotoxicity, direct administration of CMS to the site of infection has been explored. Nebulized CMS is routinely used in the management of chronic airway infection in cystic fibrosis patients, and more recently also for ventilator-associated pneumonia in conjunction with intravenous CMS. Nebulized CMS results in minimal plasma levels of colistin. ${ }^{111}$ Observational studies generally suggest that the addition of nebulized CMS to intravenous CMS may expedite clearance of $A$. baumannii from the airway but do not result in survival gain. ${ }^{112,113}$ Likewise, a randomized, open-label trial comparing the efficacy of nebulized CMS for 100 patients with gram-negative ventilator-associated pneumonia, $60 \%$ of which were caused by $A$. baumannii, also showed favorable microbiological outcome in $60.9 \%$ of the nebulized plus intravenous CMS group and $38.2 \%$ of the intravenous CMS only group ( $p=0.03$ ), but the study did not show difference in the rates of favorable clinical outcome (51.0 vs. $53.1 \%$; $p=0.84) .{ }^{114}$ However, more bronchospasm events were 
observed in the nebulized CMS group (7.8 vs. $2.0 \% ; p=0.36$ ). Overall, the clinical benefit of nebulized CMS has not been definitively established.

Colistin has very low penetration into the cerebrospinal fluid, thus intravenous CMS therapy is not expected to be effective for infection of the central nervous system. ${ }^{115,116}$ Patients with severe and/or resistant $A$. baumannii CNS infections have been treated with intrathecal or intraventricular colistin. ${ }^{117}$ In one recent case series, intraventricular CMS therapy led to cure of ventriculitis and meningitis in all six patients, with sterilization of the cerebrospinal fluid in a median of 2.5 days. ${ }^{118}$ Therefore, intrathecal or intraventricular administration of CMS should be considered along with intravenous CMS for central nervous system infection due to A. baumannii that is resistant to agents with good cerebrospinal fluid penetration, including carbapenems.

The concerns over the unique pharmacokinetics of CMS and colistin have led to renewed interest in polymyxin B, which is given as the active drug and possesses more predictable pharmacokinetic properties. ${ }^{119}$ Furthermore, several observational studies have reported lower nephrotoxicity rates with polymyxin B compared with CMS. ${ }^{120,121}$ However, studies comparing the clinical efficacy of these two agents are lacking.

\section{Tigecycline}

Tigecycline is a semisynthetic derivative of minocycline that inhibits protein synthesis by binding to the $30 \mathrm{~S}$ ribosomal subunit. It is stable against many of the tetracycline resistance mechanisms including efflux pumps, such as Tet(A-E) and Tet $(\mathrm{K})$, and also ribosomal protection, such as $\operatorname{Tet}(\mathrm{O})$ and $\operatorname{Tet}(\mathrm{M})$, thus has a broader spectrum of activity compared with the earlier tetracyclines. ${ }^{122}$ Resistance to tigecycline is relatively rare in A. baumannii, but it may develop through overexpression of efflux pumps. ${ }^{123-125}$

The killing activity of tigecycline is predicted by fAUC/MIC as with colistin. ${ }^{126}$ Tigecycline has unique pharmacokinetics with a large volume of distribution resulting in a low serum peak concentration of up to $0.8 \mu \mathrm{g} / \mathrm{mL}$ after the standard loading dose of $100 \mathrm{mg} .{ }^{127}$ Suboptimal clinical outcome (56\% infection-related mortality) has been reported for patients with carbapenem-resistant $A$. baumannii bloodstream infection who were treated with tigecycline despite in vitro susceptibility, ${ }^{128}$ and breakthrough bacteremia during therapy has also been observed. ${ }^{125}$ The use of tigecycline alone in the treatment of bacteremia is not recommended for these reasons. In addition, a phase 3 trial reported a lower clinical response rate in comparison with imipenem among patients with ventilator-associated pneumonia by $A$. baumannii when the standard approved dose was used. ${ }^{129}$ When higher doses of tigecycline ( $100 \mathrm{mg}$ twice a day or $75 \mathrm{mg}$ twice a day) were used for hospital-acquired pneumonia, they achieved comparable clinical response rate as with imipenem $(85,70,75 \%$, respectively). ${ }^{130}$ These data suggest that the currently approved dose may not be sufficient for the treatment of bacteremia and hospital-acquired pneumonia when used alone.
The largest case series on the use of tigecycline for XDR A. baumannii infections described 266 patients who were treated with tigecycline alone or in combination with another agent (a carbapenem, expanded-spectrum cephalosporin, or piperacillin-tazobactam) and 120 patients who were treated with imipenem and sulbactam. ${ }^{131}$ In both arms, the isolates were resistant to all antibiotics tested, except tigecycline and colistin. The patients who received tigecycline were significantly less likely to be in an ICU, less likely to be febrile, had lower serum creatinine, less likely to have sepsis, more likely to have pneumonia (64.7 vs. $31.7 \%$ ), and less likely to have bacteremia (18.0 vs. $43.3 \%$ ) compared with those who received imipenem and sulbactam. There was no difference in 30 -day mortality between the two groups ( 44.7 vs. $46.7 \%$ ), whereas favorable clinical outcome was more common in the tigecycline group (69.2 vs. $50.0 \%, p<0.001)$. The latter finding needs to be interpreted with caution, however, as the patients in the tigecycline group were generally less ill, the majority of them also received other agents in addition to tigecycline, and the patients in the non-tigecycline group were not on any active agents in vitro.

\section{Sulbactam}

Sulbactam is a $\beta$-lactamase inhibitor and also has affinity for penicillin-binding proteins of $A$. baumannii and is active against this species. ${ }^{132,133}$ Ampicillin-sulbactam susceptibility of $63.6 \%$ has been reported for Acinetobacter spp. isolates collected from U.S. hospitals in the early $2000 .{ }^{134}$ However, a steady decline in the susceptibility rate of $A$. baumannii from $89 \%$ in 2003 to $40 \%$ in 2008 was reported from hospitals in Michigan, raising concerns for development of resistance as more sulbactam is used for treatment of A. baumannii infections. ${ }^{135}$

The bactericidal activity of $A$. baumannii correlates best with the time that the free drug concentration remains above the MIC (fT > MIC). ${ }^{136}$ While the standard dose of ampicillinsulbactam is $12 \mathrm{~g}$ a day, it has been suggested that a dose as high as $27 \mathrm{~g}$ of ampicillin-sulbactam (i.e., $9 \mathrm{~g}$ of sulbactam) a day using extended infusion may be needed to achieve adequate exposure for treatment of infection due to less susceptible strains (MICs, $32 / 16$ to $64 / 32 \mu \mathrm{g} / \mathrm{mL}$ ). ${ }^{137,138}$

A small controlled study was conducted in Greece to determine the efficacy of ampicillin-sulbactam in 28 patients with ventilator-associated pneumonia due to XDR A. baumannii. ${ }^{139}$ All isolates were resistant to ampicillin-sulbactam and susceptible to colistin. The patients were randomized to receive either ampicillin-sulbactam ( $9 \mathrm{~g}$ of sulbactam/day) or colistin $(270 \mathrm{mg} /$ day). The clinical response rates were comparable with $76.8 \%$ for ampicillin-sulbactam versus $73.3 \%$ for colistin. Bacteriological success rates, 14- and 28-day mortality rates, and the rates of adverse events were also comparable between the two groups. The study suggested that, consistent with the pharmacokinetic data, a high dose of ampicillin-sulbactam may be efficacious in the treatment of invasive $A$. baumannii infection.

Several observational studies have attempted to explore the efficacy of ampicillin-sulbactam. In a series of A. baumannii ventilator-associated pneumonia from the United States, 
14 patients were treated with ampicillin-sulbactam and 63 with imipenem. ${ }^{140}$ The percentages of successfully treated episodes were similar in the two groups (93 vs. 83\%). There were also no differences in the rates of microbiological clearance and mortality. Dosing information was not provided in either of these studies. A study from Brazil examined the efficacy of ampicillin-sulbactam and polymyxins (colistin or polymyxin B) against invasive carbapenem-resistant $A$. baumannii infections, where 85 patients received ampicillinsulbactam and 82 received polymyxins. ${ }^{141}$ Almost 30\% also received a carbapenem in both groups, despite all isolates demonstrating carbapenem resistance in vitro. Clinical response was observed in $60 \%$ of the ampicillin-sulbactam group and $39 \%$ of the polymyxin group, and treatment with polymyxins was an independent risk factor for in-hospital mortality (odds ratio, 2.07; $p=0.04$ ). However, the median daily dose of colistin was approximately $150 \mathrm{mg}$, which is substantially lower than the currently recommended dose of up to $300 \mathrm{mg}$ a day. ${ }^{107}$ The median daily dose of ampicillinsulbactam was $9 \mathrm{~g}$.

These data suggest that the use of sulbactam-containing regimens may have a role in the treatment of infections caused by XDR $A$. baumannii, with efficacy that is at least comparable with polymyxins.

\section{Rifampin}

A potential benefit of adding rifampin to colistin has been demonstrated for $A$. baumannii in multiple in vitro and in vivo studies. ${ }^{142-145}$ Two prospective clinical trials have been conducted to test the clinical efficacy of this combination. In Turkey, 43 patients with ventilator-associated pneumonia due to carbapenem-resistant $A$. baumannii were randomized to colistin alone or colistin and rifampin. ${ }^{146}$ These two groups were comparable except for the higher mean Sequential Organ Failure Assessment score in the combination group. The crude in-hospital mortality and pneumonia-related mortality were higher for the colistin-alone group (72.7 and 63.6\%, respectively) compared with the combination group (61.9 and 38.1\%, respectively), but the differences were not statistically significant. Twenty-three percent developed nephrotoxicity, but none had hepatotoxicity from rifampin. The other study was conducted in Italy comparing the same regimens. ${ }^{147} \mathrm{~A}$ total of 210 patients with life-threatening infection due to XDR $A$. baumannii were enrolled. The study was powered to detect $20 \%$ absolute difference in 30-day mortality. The baseline characteristics were comparable, with most patients located in ICUs. There was no mortality difference between the two groups ( $43.4 \%$ for the combination group, $42.9 \%$ for the colistin group). This was the case even when patients who had rifampin-resistant isolates were excluded. However, the microbiologic eradication rate was significantly higher in the combination group ( 60.6 vs. $44.8 \%, p=0.034$ ). On the other hand, there was a trend for a higher rate of hepatic dysfunction in the combination group (20.8 vs. $11.9 \%$ ). Notably, meropenem was added in the colistin group more frequently than in the combination group (15.9 vs. 3.9\%), which may have improved the outcome in the colistin group.
Overall, the beneficial effect of adding rifampin to colistin in the treatment of XDR A. baumannii infection has been suggested by in vitro and in vivo studies, but has not been demonstrated in two randomized, controlled trials.

\section{Fosfomycin}

Fosfomycin, a peptidoglycan biosynthesis inhibitor, is not active against $A$. baumannii, but in vitro synergy has been reported between fosfomycin and colistin or sulbactam among carbapenem-resistant $A$. baumannii. ${ }^{148,149}$ Based on these observations, a randomized trial of colistin alone and colistin plus fosfomycin was conducted for infections caused by carbapenem-resistant $A$. baumannii in Thailand. ${ }^{150}$ In this study, 99 patients were enrolled and 94 were included in the analysis, 47 in each group. Fosfomycin was given at 4 g every 12 hours intravenously to patients in the combination arm, and colistin was given at $5 \mathrm{mg} / \mathrm{kg} / \mathrm{d}$ to both groups for 7 to 14 days. The combination and colistin-only groups did not differ in favorable clinical outcomes (59.6 vs. 55.3\%) or mortality at 28 days (46.8 vs. $57.4 \%$ ). However, microbiological eradication rates at the end of treatment were significantly higher in the combination group (100 vs. $81.2 \%$, $p=0.01$ ). The study was underpowered to detect a relevant difference in mortality, but given the trend for lower mortality with the addition of fosfomycin, this combination may merit further investigation.

\section{Combination Therapy}

Several retrospective studies have documented lower mortality rates after XDR A. baumannii infection when more than one agent was given for therapy. In a large retrospective study from Turkey, the clinical outcome of patients with XDR A. baumannii bloodstream infections was investigated. ${ }^{18}$ Thirty-six of them received colistin monotherapy, whereas 214 received various agents in addition to colistin (102 with a carbapenem, 69 with ampicillin-sulbactam or sulbactam, and 43 with other agents). The baseline characteristics were comparable among the groups, and all isolates were susceptible to colistin. The in-hospital mortality rate was significantly lower in the combination group than in the monotherapy group (52.3 vs. $72.2 \%, p=0.03$ ), and the rate of microbiological eradication was also significantly higher in the combination group than in the monotherapy group (79.9 vs. $55.6 \%, p=0.001$ ). In another observational study of 69 patients with solid organ transplantation who developed invasive XDR A. baumannii infection, treatment with a combination of colistin and a carbapenem was an independent predictor of survival. ${ }^{151}$ On the contrary, in a recent multicenter prospective study of 101 patients with MDR A. baumannii sepsis from Spain, there was no difference in the allcause 30-day mortality between those who received combination therapy (24.2\%) and monotherapy (23.5\%). ${ }^{152}$ The combinations used in this study included, but were not limited to, colistin plus tigecycline and carbapenem plus tigecycline. Therefore, it is not yet clear if any specific 
combinations of agents would provide survival benefit for those with XDR A. baumannii infection.

\section{Conclusion}

A. baumannii has become one of the most problematic hospital-acquired pathogens in the last two decades, helped by its extraordinary ability to accumulate antimicrobial resistance and survive in the modern healthcare environment. An increasing number of $A$. baumannii genome sequences, animal models of disease combined with bacterial mutagenesis, have provided some valuable insights into mechanisms of $A$. baumannii pathogenesis. Early detection and implementation of rigorous infection control measures is a key in preventing major outbreaks due to this organism. Carbapenems have been considered the agents of choice for infections caused by susceptible pathogens, but the rapid increase in carbapenem resistance rates has complicated this issue. The backbone agents when treating carbapenem-resistant cases include polymyxins, tigecycline, and sulbactam. Among these, colistin is the best studied to date, particularly in terms of its pharmacokinetics and pharmacodynamics. Therefore, the most standard approach currently is to treat these infections with pharmacokinetically optimized doses of colistin (including a loading dose), with or without a second agent, particularly a carbapenem, tigecycline, or sulbactam. Nonetheless, there is still a dearth of clinical data to guide clinicians and many questions remain unanswered. It is hoped that ongoing clinical trials and high-quality prospective observational studies will address these questions and improve the care of patients affected by this difficult-to-treat pathogen.

\section{Acknowledgments}

Y.D.'s effort was supported in part by research grants from the National Institutes of Health (R01AI104895, R21AI107302). A.Y.P would like to acknowledge support from an Australian National Health and Medical Research Council Career Development Fellowship (APP1047916).

\section{References}

1 Neidell MJ, Cohen B, Furuya Y, et al. Costs of healthcare- and community-associated infections with antimicrobial-resistant versus antimicrobial-susceptible organisms. Clin Infect Dis 2012;55(6):807-815

2 Lautenbach E, Synnestvedt M, Weiner MG, et al. Epidemiology and impact of imipenem resistance in Acinetobacter baumannii. Infect Control Hosp Epidemiol 2009;30(12):1186-1192

3 Peleg AY, Seifert H, Paterson DL. Acinetobacter baumannii: emergence of a successful pathogen. Clin Microbiol Rev 2008;21(3): 538-582

4 Abbott I, Cerqueira GM, Bhuiyan S, Peleg AY. Carbapenem resistance in Acinetobacter baumannii: laboratory challenges, mechanistic insights and therapeutic strategies. Expert Rev Anti Infect Ther 2013;11(4):395-409

5 Chuang YC, Sheng WH, Li SY, et al. Influence of genospecies of Acinetobacter baumannii complex on clinical outcomes of patients with Acinetobacter bacteremia. Clin Infect Dis 2011;52(3):352-360

6 Queenan AM, Pillar CM, Deane J, et al. Multidrug resistance among Acinetobacter spp. in the USA and activity profile of key agents: results from CAPITAL Surveillance 2010. Diagn Microbiol Infect Dis 2012;73(3):267-270

7 Sievert DM, Ricks P, Edwards JR, et al; National Healthcare Safety Network (NHSN) Team and Participating NHSN Facilities. Antimicrobial-resistant pathogens associated with healthcare-associated infections: summary of data reported to the National Healthcare Safety Network at the Centers for Disease Control and Prevention, 2009-2010. Infect Control Hosp Epidemiol 2013; 34(1):1-14

8 Bergogne-Bérézin E, Towner KJ. Acinetobacter spp. as nosocomial pathogens: microbiological, clinical, and epidemiological features. Clin Microbiol Rev 1996;9(2):148-165

9 Cai Y, Chai D, Wang R, Liang B, Bai N. Colistin resistance of Acinetobacter baumannii: clinical reports, mechanisms and antimicrobial strategies. J Antimicrob Chemother 2012;67(7):1607-1615

10 Zarrilli R, Pournaras S, Giannouli M, Tsakris A. Global evolution of multidrug-resistant Acinetobacter baumannii clonal lineages. Int J Antimicrob Agents 2013;41(1):11-19

11 Higgins PG, Dammhayn C, Hackel M, Seifert H. Global spread of carbapenem-resistant Acinetobacter baumannii. J Antimicrob Chemother 2010;65(2):233-238

12 Ng TM, Teng CB, Lye DC, Apisarnthanarak A. A multicenter casecase control study for risk factors and outcomes of extensively drug-resistant Acinetobacter baumannii bacteremia. Infect Control Hosp Epidemiol 2014;35(1):49-55

13 Sheng WH, Liao CH, Lauderdale TL, et al. A multicenter study of risk factors and outcome of hospitalized patients with infections due to carbapenem-resistant Acinetobacter baumannii. Int J Infect Dis 2010;14(9):e764-e769

14 Cisneros JM, Rodríguez-Baño J, Fernández-Cuenca F, et al; Spanish Group for Nosocomial Infection (GEIH) for the Spanish Society of Infectious Diseases and Clinical Microbiology (SEIMC). Risk-factors for the acquisition of imipenem-resistant Acinetobacter baumannii in Spain: a nationwide study. Clin Microbiol Infect 2005;11(11):874-879

15 Lee SO, Kim NJ, Choi SH, et al. Risk factors for acquisition of imipenem-resistant Acinetobacter baumannii: a case-control study. Antimicrob Agents Chemother 2004;48(1):224-228

16 Lemos EV, de la Hoz FP, Einarson TR, et al. Carbapenem resistance and mortality in patients with Acinetobacter baumannii infection: systematic review and meta-analysis. Clin Microbiol Infect 2014;20(5):416-423

17 Kim YJ, Kim SI, Hong KW, Kim YR, Park YJ, Kang MW. Risk factors for mortality in patients with carbapenem-resistant Acinetobacter baumannii bacteremia: impact of appropriate antimicrobial therapy. J Korean Med Sci 2012;27(5):471-475

18 Batirel A, Balkan II, Karabay O, et al. Comparison of colistincarbapenem, colistin-sulbactam, and colistin plus other antibacterial agents for the treatment of extremely drug-resistant Acinetobacter baumannii bloodstream infections. Eur J Clin Microbiol Infect Dis 2014;33(8):1311-1322

19 Lee HY, Chen CL, Wu SR, Huang CW, Chiu CH. Risk factors and outcome analysis of Acinetobacter baumannii complex bacteremia in critical patients. Crit Care Med 2014;42(5):1081-1088

20 Kim SY, Jung JY, Kang YA, et al. Risk factors for occurrence and 30day mortality for carbapenem-resistant Acinetobacter baumannii bacteremia in an intensive care unit. J Korean Med Sci 2012; 27(8):939-947

21 Esterly JS, Griffith M, Qi C, Malczynski M, Postelnick MJ, Scheetz $\mathrm{MH}$. Impact of carbapenem resistance and receipt of active antimicrobial therapy on clinical outcomes of Acinetobacter baumannii bloodstream infections. Antimicrob Agents Chemother 2011;55(10):4844-4849

22 Munoz-Price LS, Zembower T, Penugonda S, et al. Clinical outcomes of carbapenem-resistant Acinetobacter baumannii bloodstream infections: study of a 2-state monoclonal outbreak. Infect Control Hosp Epidemiol 2010;31(10):1057-1062 
23 Smith MG, Gianoulis TA, Pukatzki S, et al. New insights into Acinetobacter baumannii pathogenesis revealed by high-density pyrosequencing and transposon mutagenesis. Genes Dev 2007; 21(5):601-614

24 Choi CH, Lee JS, Lee YC, Park TI, Lee JC. Acinetobacter baumannii invades epithelial cells and outer membrane protein A mediates interactions with epithelial cells. BMC Microbiol 2008;8:216

25 Rumbo C, Tomás M, Fernández Moreira E, et al. The Acinetobacter baumannii Omp33-36 porin is a virulence factor that induces apoptosis and modulates autophagy in human cells. Infect Immun 2014;82(11):4666-4680

26 Smani Y, Dominguez-Herrera J, Pachón J. Association of the outer membrane protein Omp33 with fitness and virulence of Acinetobacter baumannii. J Infect Dis 2013;208(10):1561-1570

27 Russo TA, Luke NR, Beanan JM, et al. The K1 capsular polysaccharide of Acinetobacter baumannii strain 307-0294 is a major virulence factor. Infect Immun 2010;78(9):3993-4000

28 Luke NR, Sauberan SL, Russo TA, et al. Identification and characterization of a glycosyltransferase involved in Acinetobacter baumannii lipopolysaccharide core biosynthesis. Infect Immun 2010;78(5):2017-2023

29 Jacobs AC, Hood I, Boyd KL, et al. Inactivation of phospholipase D diminishes Acinetobacter baumannii pathogenesis. Infect Immun 2010;78(5):1952-1962

30 Gaddy JA, Arivett BA, McConnell MJ, López-Rojas R, Pachón J, Actis LA. Role of acinetobactin-mediated iron acquisition functions in the interaction of Acinetobacter baumannii strain ATCC 19606T with human lung epithelial cells, Galleria mellonella caterpillars, and mice. Infect Immun 2012;80(3):1015-1024

31 Cerqueira GM, Kostoulias X, Khoo C, et al. A global virulence regulator in Acinetobacter baumannii and its control of the phenylacetic acid catabolic pathway. J Infect Dis 2014;210(1): 46-55

32 de Breij A, Dijkshoorn L, Lagendijk E, et al. Do biofilm formation and interactions with human cells explain the clinical success of Acinetobacter baumannii? PLoS ONE 2010;5(5):e10732

33 Longo F, Vuotto C, Donelli G. Biofilm formation in Acinetobacter baumannii. New Microbiol 2014;37(2):119-127

34 Høiby N, Ciofu O, Johansen HK, et al. The clinical impact of bacterial biofilms. Int J Oral Sci 2011;3(2):55-65

35 Davenport EK, Call DR, Beyenal H. Differential protection from tobramycin by extracellular polymeric substances from Acinetobacter baumannii and Staphylococcus aureus biofilms. Antimicrob Agents Chemother 2014;58(8):4755-4761

36 Lee JC, Koerten H, van den Broek P, et al. Adherence of Acinetobacter baumannii strains to human bronchial epithelial cells. Res Microbiol 2006;157(4):360-366

37 Gaddy JA, Tomaras AP, Actis LA. The Acinetobacter baumannii 19606 OmpA protein plays a role in biofilm formation on abiotic surfaces and in the interaction of this pathogen with eukaryotic cells. Infect Immun 2009;77(8):3150-3160

38 Smani Y, McConnell MJ, Pachón J. Role of fibronectin in the adhesion of Acinetobacter baumannii to host cells. PLoS ONE 2012;7(4):e33073

39 Bentancor LV, Camacho-Peiro A, Bozkurt-Guzel C, Pier GB, MairaLitrán T. Identification of Ata, a multifunctional trimeric autotransporter of Acinetobacter baumannii.J Bacteriol 2012;194(15): 3950-3960

40 Lee JS, Choi CH, Kim JW, Lee JC. Acinetobacter baumannii outer membrane protein A induces dendritic cell death through mitochondrial targeting. J Microbiol 2010;48(3):387-392

41 Choi CH, Lee EY, Lee YC, et al. Outer membrane protein 38 of Acinetobacter baumannii localizes to the mitochondria and induces apoptosis of epithelial cells. Cell Microbiol 2005;7(8):1127-1138

42 García A, Solar H, González C, Zemelman R. Effect of EDTA on the resistance of clinical isolates of Acinetobacter baumannii to the bactericidal activity of normal human serum. J Med Microbiol 2000;49(11):1047-1050
43 Moffatt JH, Harper M, Mansell A, et al. Lipopolysaccharide-deficient Acinetobacter baumannii shows altered signaling through host Toll-like receptors and increased susceptibility to the host antimicrobial peptide LL-37. Infect Immun 2013;81(3):684-689

$44 \mathrm{Kim}$ SW, Choi CH, Moon DC, et al. Serum resistance of Acinetobacter baumannii through the binding of factor $\mathrm{H}$ to outer membrane proteins. FEMS Microbiol Lett 2009;301(2):224-231

45 King LB, Swiatlo E, Swiatlo A, McDaniel LS. Serum resistance and biofilm formation in clinical isolates of Acinetobacter baumannii. FEMS Immunol Med Microbiol 2009;55(3):414-421

46 King LB, Pangburn MK, McDaniel LS. Serine protease PKF of Acinetobacter baumannii results in serum resistance and suppression of biofilm formation. J Infect Dis 2013;207(7): $1128-1134$

47 Liou ML, Soo PC, Ling SR, Kuo HY, Tang CY, Chang KC. The sensor kinase BfmS mediates virulence in Acinetobacter baumannii. J Microbiol Immunol Infect 2014;47(4):275-281

48 Eijkelkamp BA, Stroeher UH, Hassan KA, Elbourne LD, Paulsen IT, Brown MH. H-NS plays a role in expression of Acinetobacter baumannii virulence features. Infect Immun 2013;81(7): 2574-2583

49 Wang N, Ozer EA, Mandel MJ, Hauser AR. Genome-wide identification of Acinetobacter baumannii genes necessary for persistence in the lung. MBio 2014;5(3):e01163-e14

50 van Faassen H, KuoLee R, Harris G, Zhao X, Conlan JW, Chen W. Neutrophils play an important role in host resistance to respiratory infection with Acinetobacter baumannii in mice. Infect Immun 2007;75(12):5597-5608

51 Breslow JM, Meissler JJ Jr, Hartzell RR, et al. Innate immune responses to systemic Acinetobacter baumannii infection in mice: neutrophils, but not interleukin-17, mediate host resistance. Infect Immun 2011;79(8):3317-3327

52 Qiu H, KuoLee R, Harris G, Van Rooijen N, Patel GB, Chen W. Role of macrophages in early host resistance to respiratory Acinetobacter baumannii infection. PLoS ONE 2012;7(6):e40019

53 Knapp S, Wieland CW, Florquin S, et al. Differential roles of CD14 and toll-like receptors 4 and 2 in murine Acinetobacter pneumonia. Am J Respir Crit Care Med 2006;173(1):122-129

$54 \mathrm{Kim} \mathrm{CH}$, Jeong YJ, Lee J, et al. Essential role of toll-like receptor 4 in Acinetobacter baumannii-induced immune responses in immune cells. Microb Pathog 2013;54:20-25

55 Erridge C, Moncayo-Nieto OL, Morgan R, Young M, Poxton IR. Acinetobacter baumannii lipopolysaccharides are potent stimulators of human monocyte activation via Toll-like receptor 4 signalling. J Med Microbiol 2007;56(Pt 2):165-171

56 Bist P, Dikshit N, Koh TH, Mortellaro A, Tan TT, Sukumaran B. The Nod1, Nod2, and Rip2 axis contributes to host immune defense against intracellular Acinetobacter baumannii infection. Infect Immun 2014;82(3):1112-1122

57 McConnell MJ, Domínguez-Herrera J, Smani Y, López-Rojas R, Docobo-Pérez F, Pachón J. Vaccination with outer membrane complexes elicits rapid protective immunity to multidrug-resistant Acinetobacter baumannii. Infect Immun 2011;79(1):518-526

58 Fajardo Bonin R, Chapeaurouge A, Perales J, et al. Identification of immunogenic proteins of the bacterium Acinetobacter baumannii using a proteomic approach. Proteomics Clin Appl 2014;8(11-12): 916-923

59 Luo G, Lin L, Ibrahim AS, et al. Active and passive immunization protects against lethal, extreme drug resistant-Acinetobacter baumannii infection. PLoS ONE 2012;7(1):e29446

60 Hujer KM, Hamza NS, Hujer AM, et al. Identification of a new allelic variant of the Acinetobacter baumannii cephalosporinase, ADC-7 $\beta$-lactamase: defining a unique family of class $C$ enzymes. Antimicrob Agents Chemother 2005;49(7):2941-2948

61 Bou G, Martínez-Beltrán J. Cloning, nucleotide sequencing, and analysis of the gene encoding an AmpC $\beta$-lactamase in Acinetobacter baumannii. Antimicrob Agents Chemother 2000;44(2): 428-432 
62 Héritier C, Poirel L, Nordmann P. Cephalosporinase over-expression resulting from insertion of ISAba1 in Acinetobacter baumannii. Clin Microbiol Infect 2006;12(2):123-130

63 Lopes BS, Amyes SG. Role of ISAba 1 and ISAba125 in governing the expression of bla $a_{\mathrm{ADC}}$ in clinically relevant Acinetobacter baumannii strains resistant to cephalosporins. J Med Microbiol 2012;61 (Pt 8):1103-1108

64 Vahaboglu H, Oztürk R, Aygün G, et al. Widespread detection of PER-1-type extended-spectrum $\beta$-lactamases among nosocomial Acinetobacter and Pseudomonas aeruginosa isolates in Turkey: a nationwide multicenter study. Antimicrob Agents Chemother 1997;41(10):2265-2269

65 Lee Y, Bae IK, Kim J, Jeong SH, Lee K. Dissemination of ceftazidimeresistant Acinetobacter baumannii clonal complex 92 in Korea. J Appl Microbiol 2012;112(6):1207-1211

66 Naas T, Coignard B, Carbonne A, et al; French Nosocomial Infection Early Warning Investigation and Surveillance Network. VEB1 Extended-spectrum $\beta$-lactamase-producing Acinetobacter baumannii, France. Emerg Infect Dis 2006;12(8):1214-1222

67 Adams-Haduch JM, Paterson DL, Sidjabat HE, et al. Genetic basis of multidrug resistance in Acinetobacter baumannii clinical isolates at a tertiary medical center in Pennsylvania. Antimicrob Agents Chemother 2008;52(11):3837-3843

68 Turton JF, Ward ME, Woodford N, et al. The role of ISAba1 in expression of OXA carbapenemase genes in Acinetobacter baumannii. FEMS Microbiol Lett 2006;258(1):72-77

69 Figueiredo S, Poirel L, Papa A, Koulourida V, Nordmann P. Overexpression of the naturally occurring bla $a_{\mathrm{OXA}-51}$ gene in Acinetobacter baumannii mediated by novel insertion sequence ISAba9. Antimicrob Agents Chemother 2009;53(9):4045-4047

70 Higgins PG, Pérez-Llarena FJ, Zander E, Fernández A, Bou G, Seifert H. OXA-235, a novel class D $\beta$-lactamase involved in resistance to carbapenems in Acinetobacter baumannii. Antimicrob Agents Chemother 2013;57(5):2121-2126

71 Mugnier PD, Poirel L, Naas T, Nordmann P. Worldwide dissemination of the bla $a_{\mathrm{OXA}-23}$ carbapenemase gene of Acinetobacter baumannii. Emerg Infect Dis 2010;16(1):35-40

72 Chen Y, Zhou Z, Jiang Y, Yu Y. Emergence of NDM-1-producing Acinetobacter baumannii in China. J Antimicrob Chemother 2011; 66(6):1255-1259

73 Decousser JW, Jansen C, Nordmann P, et al. Outbreak of NDM-1producing Acinetobacter baumannii in France, January to May 2013. Euro Surveill 2013;18(31):20547

74 Tsakris A, Ikonomidis A, Pournaras S, et al. VIM- 1 metallo- $\beta$ lactamase in Acinetobacter baumannii. Emerg Infect Dis 2006; 12(6):981-983

75 Kouyama Y, Harada S, Ishii Y, et al. Molecular characterization of carbapenem-non-susceptible Acinetobacter spp. in Japan: predominance of multidrug-resistant Acinetobacter baumannii clonal complex 92 and IMP-type metallo- $\beta$-lactamase-producing non-baumannii Acinetobacter species. J Infect Chemother 2012; 18(4):522-528

76 Lee K, Yum JH, Yong D, et al. Novel acquired metallo- $\beta$-lactamase gene, bla $_{\mathrm{SIM}-1}$, in a class 1 integron from Acinetobacter baumannii clinical isolates from Korea. Antimicrob Agents Chemother 2005; 49(11):4485-4491

77 Robledo IE, Aquino EE, Santé MI, et al. Detection of KPC in Acinetobacter spp. in Puerto Rico. Antimicrob Agents Chemother 2010;54(3):1354-1357

78 Urban C, Go E, Mariano N, Rahal JJ. Interaction of sulbactam, clavulanic acid and tazobactam with penicillin-binding proteins of imipenem-resistant and -susceptible Acinetobacter baumannii. FEMS Microbiol Lett 1995;125:193-198

79 Fernández-Cuenca F, Martínez-Martínez L, Conejo MC, Ayala JA, Perea EJ, Pascual A. Relationship between $\beta$-lactamase production, outer membrane protein and penicillin-binding protein profiles on the activity of carbapenems against clinical isolates of Acinetobacter baumannii. J Antimicrob Chemother 2003;51(3): 565-574

80 Krizova L, Poirel L, Nordmann P, Nemec A. TEM-1 $\beta$-lactamase as a source of resistance to sulbactam in clinical strains of Acinetobacter baumannii. J Antimicrob Chemother 2013;68(12): 2786-2791

81 Giannouli M, Di Popolo A, Durante-Mangoni E, et al. Molecular epidemiology and mechanisms of rifampicin resistance in Acinetobacter baumannii isolates from Italy. Int J Antimicrob Agents 2012;39(1):58-63

82 Houang ET, Chu YW, Lo WS, Chu KY, Cheng AF. Epidemiology of rifampin ADP-ribosyltransferase (arr-2) and metallo- $\beta$-lactamase $\left(b a_{\mathrm{IMP}-4}\right)$ gene cassettes in class 1 integrons in Acinetobacter strains isolated from blood cultures in 1997 to 2000. Antimicrob Agents Chemother 2003;47(4):1382-1390

83 Shaw KJ, Rather PN, Hare RS, Miller GH. Molecular genetics of aminoglycoside resistance genes and familial relationships of the aminoglycoside-modifying enzymes. Microbiol Rev 1993;57(1): 138-163

84 Landman D, Kelly P, Bäcker M, et al. Antimicrobial activity of a novel aminoglycoside, ACHN-490, against Acinetobacter baumannii and Pseudomonas aeruginosa from New York City. J Antimicrob Chemother 2011;66(2):332-334

85 Akers KS, Chaney C, Barsoumian A, et al. Aminoglycoside resistance and susceptibility testing errors in Acinetobacter baumannii-calcoaceticus complex. J Clin Microbiol 2010;48(4):1132-1138

86 Liou GF, Yoshizawa S, Courvalin P, Galimand M. Aminoglycoside resistance by ArmA-mediated ribosomal 16S methylation in human bacterial pathogens. J Mol Biol 2006;359(2):358-364

87 Yu YS, Zhou H, Yang Q, Chen YG, Li LJ. Widespread occurrence of aminoglycoside resistance due to ArmA methylase in imipenemresistant Acinetobacter baumannii isolates in China. J Antimicrob Chemother 2007;60(2):454-455

88 Doi Y, Adams JM, Yamane K, Paterson DL. Identification of $16 \mathrm{~S}$ rRNA methylase-producing Acinetobacter baumannii clinical strains in North America. Antimicrob Agents Chemother 2007; 51(11):4209-4210

89 Coyne S, Rosenfeld N, Lambert T, Courvalin P, Périchon B. Overexpression of resistance-nodulation-cell division pump AdeFGH confers multidrug resistance in Acinetobacter baumannii. Antimicrob Agents Chemother 2010;54(10):4389-4393

90 Beceiro A, Llobet E, Aranda J, et al. Phosphoethanolamine modification of lipid A in colistin-resistant variants of Acinetobacter baumannii mediated by the pmrAB two-component regulatory system. Antimicrob Agents Chemother 2011;55(7):3370-3379

91 Pelletier MR, Casella LG, Jones JW, et al. Unique structural modifications are present in the lipopolysaccharide from colistin-resistant strains of Acinetobacter baumannii. Antimicrob Agents Chemother 2013;57(10):4831-4840

92 Arroyo LA, Herrera CM, Fernandez L, Hankins JV, Trent MS, Hancock RE. The pmrCAB operon mediates polymyxin resistance in Acinetobacter baumannii ATCC 17978 and clinical isolates through phosphoethanolamine modification of lipid A. Antimicrob Agents Chemother 2011;55(8):3743-3751

93 Moffatt JH, Harper M, Harrison P, et al. Colistin resistance in Acinetobacter baumannii is mediated by complete loss of lipopolysaccharide production. Antimicrob Agents Chemother 2010; 54(12):4971-4977

94 Chopra I, Hawkey PM, Hinton M. Tetracyclines, molecular and clinical aspects. J Antimicrob Chemother 1992;29(3):245-277

95 Coyne S, Courvalin P, Périchon B. Efflux-mediated antibiotic resistance in Acinetobacter spp. Antimicrob Agents Chemother 2011;55(3):947-953

96 Jawad A, Seifert H, Snelling AM, Heritage J, Hawkey PM. Survival of Acinetobacter baumannii on dry surfaces: comparison of outbreak and sporadic isolates. J Clin Microbiol 1998;36(7): 1938-1941 
97 Thom KA, Johnson JK, Lee MS, Harris AD. Environmental contamination because of multidrug-resistant Acinetobacter baumannii surrounding colonized or infected patients. Am J Infect Control 2011;39(9):711-715

98 Morgan DJ, Liang SY, Smith CL, et al. Frequent multidrug-resistant Acinetobacter baumannii contamination of gloves, gowns, and hands of healthcare workers. Infect Control Hosp Epidemiol 2010;31(7):716-721

99 Enfield KB, Huq NN, Gosseling MF, et al. Control of simultaneous outbreaks of carbapenemase-producing Enterobacteriaceae and extensively drug-resistant Acinetobacter baumannii infection in an intensive care unit using interventions promoted in the Centers for Disease Control and Prevention 2012 carbapenemase-resistant Enterobacteriaceae Toolkit. Infect Control Hosp Epidemiol 2014;35(7):810-817

100 Marchaim D, Navon-Venezia S, Schwartz D, et al. Surveillance cultures and duration of carriage of multidrug-resistant Acinetobacter baumannii. J Clin Microbiol 2007;45(5):1551-1555

101 Doi Y, Onuoha EO, Adams-Haduch JM, et al. Screening for Acinetobacter baumannii colonization by use of sponges. J Clin Microbiol 2011;49(1):154-158

102 Coyle JR, Kaye KS, Taylor T, et al. Effectiveness and cost of implementing an active surveillance screening policy for Acinetobacter baumannii: a Monte Carlo simulation model. Am J Infect Control 2014;42(3):283-287

103 Quale J, Shah N, Kelly P, et al. Activity of polymyxin B and the novel polymyxin analogue CB-182,804 against contemporary Gramnegative pathogens in New York City. Microb Drug Resist 2012; 18(2):132-136

104 Bergen PJ, Landersdorfer CB, Zhang J, et al. Pharmacokinetics and pharmacodynamics of 'old' polymyxins: what is new? Diagn Microbiol Infect Dis 2012;74(3):213-223

105 Owen RJ, Li J, Nation RL, Spelman D. In vitro pharmacodynamics of colistin against Acinetobacter baumannii clinical isolates. J Antimicrob Chemother 2007;59(3):473-477

106 Li J, Rayner CR, Nation RL, et al. Heteroresistance to colistin in multidrug-resistant Acinetobacter baumannii. Antimicrob Agents Chemother 2006;50(9):2946-2950

107 Garonzik SM, Li J, Thamlikitkul V, et al. Population pharmacokinetics of colistin methanesulfonate and formed colistin in critically ill patients from a multicenter study provide dosing suggestions for various categories of patients. Antimicrob Agents Chemother 2011;55(7):3284-3294

108 Plachouras D, Karvanen M, Friberg LE, et al. Population pharmacokinetic analysis of colistin methanesulfonate and colistin after intravenous administration in critically ill patients with infections caused by gram-negative bacteria. Antimicrob Agents Chemother 2009;53(8):3430-3436

109 Mohamed AF, Karaiskos I, Plachouras D, et al. Application of a loading dose of colistin methanesulfonate in critically ill patients: population pharmacokinetics, protein binding, and prediction of bacterial kill. Antimicrob Agents Chemother 2012;56(8):4241-4249

110 Garnacho-Montero J, Ortiz-Leyba C, Jiménez-Jiménez FJ, et al. Treatment of multidrug-resistant Acinetobacter baumannii ventilator-associated pneumonia (VAP) with intravenous colistin: a comparison with imipenem-susceptible VAP. Clin Infect Dis 2003; 36(9):1111-1118

111 W S Yapa S, Li J, Patel K, et al. Pulmonary and systemic pharmacokinetics of inhaled and intravenous colistin methanesulfonate in cystic fibrosis patients: targeting advantage of inhalational administration. Antimicrob Agents Chemother 2014;58(5):2570-2579

112 Tumbarello M, De Pascale G, Trecarichi EM, et al. Effect of aerosolized colistin as adjunctive treatment on the outcomes of microbiologically documented ventilator-associated pneumonia caused by colistin-only susceptible gram-negative bacteria. Chest 2013;144(6):1768-1775

113 Kuo SC, Lee YT, Yang SP, et al. Eradication of multidrug-resistant Acinetobacter baumannii from the respiratory tract with inhaled colistin methanesulfonate: a matched case-control study. Clin Microbiol Infect 2012;18(9):870-876

114 Rattanaumpawan P, Lorsutthitham J, Ungprasert P, Angkasekwinai N, Thamlikitkul V. Randomized controlled trial of nebulized colistimethate sodium as adjunctive therapy of ventilator-associated pneumonia caused by Gram-negative bacteria. J Antimicrob Chemother 2010;65(12):2645-2649

115 Markantonis SL, Markou N, Fousteri M, et al. Penetration of colistin into cerebrospinal fluid. Antimicrob Agents Chemother 2009;53(11):4907-4910

116 Ziaka M, Markantonis SL, Fousteri M, et al. Combined intravenous and intraventricular administration of colistin methanesulfonate in critically ill patients with central nervous system infection. Antimicrob Agents Chemother 2013;57(4):1938-1940

117 Imberti R, Cusato M, Accetta G, et al. Pharmacokinetics of colistin in cerebrospinal fluid after intraventricular administration of colistin methanesulfonate. Antimicrob Agents Chemother 2012;56(8):4416-4421

118 Karaiskos I, Galani L, Baziaka F, Giamarellou H. Intraventricular and intrathecal colistin as the last therapeutic resort for the treatment of multidrug-resistant and extensively drug-resistant Acinetobacter baumannii ventriculitis and meningitis: a literature review. Int J Antimicrob Agents 2013;41(6):499-508

119 Nation RL, Velkov T, Li J. Colistin and polymyxin B: peas in a pod, or chalk and cheese? Clin Infect Dis 2014;59(1):88-94

120 Akajagbor DS, Wilson SL, Shere-Wolfe KD, Dakum P, Charurat ME, Gilliam BL. Higher incidence of acute kidney injury with intravenous colistimethate sodium compared with polymyxin B in critically ill patients at a tertiary care medical center. Clin Infect Dis 2013;57(9):1300-1303

121 Phe K, Lee Y, McDaneld PM, et al. In vitro assessment and multicenter cohort study of comparative nephrotoxicity rates associated with colistimethate versus polymyxin B therapy. Antimicrob Agents Chemother 2014;58(5):2740-2746

122 Livermore DM. Tigecycline: what is it, and where should it be used? J Antimicrob Chemother 2005;56(4):611-614

123 Rumbo C, Gato E, López M, et al; Spanish Group of Nosocomial Infections and Mechanisms of Action and Resistance to Antimicrobials (GEIH-GEMARA); Spanish Society of Clinical Microbiology and Infectious Diseases (SEIMC); Spanish Network for Research in Infectious Diseases(REIPI). Contribution of efflux pumps, porins, and $\beta$-lactamases to multidrug resistance in clinical isolates of Acinetobacter baumannii. Antimicrob Agents Chemother 2013;57(11):5247-5257

124 Ruzin A, Keeney D, Bradford PA. AdeABC multidrug efflux pump is associated with decreased susceptibility to tigecycline in Acinetobacter calcoaceticus-Acinetobacter baumannii complex. J Antimicrob Chemother 2007;59(5):1001-1004

125 Peleg AY, Potoski BA, Rea R, et al. Acinetobacter baumannii bloodstream infection while receiving tigecycline: a cautionary report. J Antimicrob Chemother 2007;59(1):128-131

126 Koomanachai P, Kim A, Nicolau DP. Pharmacodynamic evaluation of tigecycline against Acinetobacter baumannii in a murine pneumonia model. J Antimicrob Chemother 2009;63(5):982-987

127 Muralidharan G, Micalizzi M, Speth J, Raible D, Troy S. Pharmacokinetics of tigecycline after single and multiple doses in healthy subjects. Antimicrob Agents Chemother 2005;49(1): 220-229

$128 \mathrm{Kim} \mathrm{NH}$, Hwang JH, Song KH, et al. Tigecycline in carbapenemresistant Acinetobacter baumannii bacteraemia: susceptibility and clinical outcome. Scand J Infect Dis 2013;45(4):315-319

129 Freire AT, Melnyk V, Kim MJ, et al; 311 Study Group. Comparison of tigecycline with imipenem/cilastatin for the treatment of hospital-acquired pneumonia. Diagn Microbiol Infect Dis 2010; 68(2):140-151

130 Ramirez J, Dartois N, Gandjini H, Yan JL, Korth-Bradley J, McGovern PC. Randomized phase 2 trial to evaluate the clinical efficacy of two high-dosage tigecycline regimens versus 
imipenem-cilastatin for treatment of hospital-acquired pneumonia. Antimicrob Agents Chemother 2013;57(4):1756-1762

131 Lee YT, Tsao SM, Hsueh PR. Clinical outcomes of tigecycline alone or in combination with other antimicrobial agents for the treatment of patients with healthcare-associated multidrug-resistant Acinetobacter baumannii infections. Eur J Clin Microbiol Infect Dis 2013;32(9):1211-1220

132 Noguchi JK, Gill MA. Sulbactam: a $\beta$-lactamase inhibitor. Clin Pharm 1988;7(1):37-51

133 Rafailidis PI, Ioannidou EN, Falagas ME. Ampicillin/sulbactam: current status in severe bacterial infections. Drugs 2007;67(13): 1829-1849

134 Swenson JM, Killgore GE, Tenover FC. Antimicrobial susceptibility testing of Acinetobacter spp. by NCCLS broth microdilution and disk diffusion methods. J Clin Microbiol 2004;42(11):5102-5108

135 Reddy T, Chopra T, Marchaim D, et al. Trends in antimicrobial resistance of Acinetobacter baumannii isolates from a metropolitan Detroit health system. Antimicrob Agents Chemother 2010; 54(5):2235-2238

136 Yokoyama Y, Matsumoto K, Ikawa K, et al. Pharmacokinetic/ pharmacodynamic evaluation of sulbactam against Acinetobacter baumannii in in vitro and murine thigh and lung infection models. Int J Antimicrob Agents 2014;43(6):547-552

137 Housman ST, Hagihara M, Nicolau DP, Kuti JL. In vitro pharmacodynamics of human-simulated exposures of ampicillin/sulbactam, doripenem and tigecycline alone and in combination against multidrug-resistant Acinetobacter baumannii. J Antimicrob Chemother 2013;68(10):2296-2304

138 Jaruratanasirikul S, Wongpoowarak W, Aeinlang N, Jullangkoon M. Pharmacodynamics modeling to optimize dosage regimens of sulbactam. Antimicrob Agents Chemother 2013;57(7):3441-3444

139 Betrosian AP, Frantzeskaki F, Xanthaki A, Douzinas EE. Efficacy and safety of high-dose ampicillin/sulbactam vs. colistin as monotherapy for the treatment of multidrug resistant Acinetobacter baumannii ventilator-associated pneumonia. J Infect 2008;56(6):432-436

140 Wood GC, Hanes SD, Croce MA, Fabian TC, Boucher BA. Comparison of ampicillin-sulbactam and imipenem-cilastatin for the treatment of acinetobacter ventilator-associated pneumonia. Clin Infect Dis 2002;34(11):1425-1430

141 Oliveira MS, Prado GV, Costa SF, Grinbaum RS, Levin AS. Ampicillin/sulbactam compared with polymyxins for the treatment of infections caused by carbapenem-resistant Acinetobacter spp. J Antimicrob Chemother 2008;61(6):1369-1375

142 Song JY, Kee SY, Hwang IS, et al. In vitro activities of carbapenem/ sulbactam combination, colistin, colistin/rifampicin combination and tigecycline against carbapenem-resistant Acinetobacter baumannii. J Antimicrob Chemother 2007;60(2):317-322

143 Giamarellos-Bourboulis EJ, Xirouchaki E, Giamarellou H. Interactions of colistin and rifampin on multidrug-resistant Acinetobacter baumannii. Diagn Microbiol Infect Dis 2001;40(3):117-120

144 Pachón-Ibáñez ME, Docobo-Pérez F, López-Rojas R, et al. Efficacy of rifampin and its combinations with imipenem, sulbactam, and colistin in experimental models of infection caused by imipenem-resistant Acinetobacter baumannii. Antimicrob Agents Chemother 2010;54(3):1165-1172

145 Pantopoulou A, Giamarellos-Bourboulis EJ, Raftogannis M, et al. Colistin offers prolonged survival in experimental infection by multidrug-resistant Acinetobacter baumannii: the significance of co-administration of rifampicin. Int J Antimicrob Agents 2007; 29(1):51-55

146 Aydemir H, Akduman D, Piskin N, et al. Colistin vs. the combination of colistin and rifampicin for the treatment of carbapenemresistant Acinetobacter baumannii ventilator-associated pneumonia. Epidemiol Infect 2013;141(6):1214-1222
147 Durante-Mangoni E, Signoriello G, Andini R, et al. Colistin and rifampicin compared with colistin alone for the treatment of serious infections due to extensively drug-resistant Acinetobacter baumannii: a multicenter, randomized clinical trial. Clin Infect Dis 2013;57(3):349-358

148 Santimaleeworagun W, Wongpoowarak P, Chayakul P, Pattharachayakul S, Tansakul P, Garey KW. In vitro activity of colistin or sulbactam in combination with fosfomycin or imipenem against clinical isolates of carbapenem-resistant Acinetobacter baumannii producing OXA-23 carbapenemases. Southeast Asian J Trop Med Public Health 2011;42(4):890-900

149 Falagas ME, Kanellopoulou MD, Karageorgopoulos DE, et al. Antimicrobial susceptibility of multidrug-resistant Gram negative bacteria to fosfomycin. Eur J Clin Microbiol Infect Dis 2008; 27(6):439-443

150 Sirijatuphat R, Thamlikitkul V. Colistin versus colistin plus fosfomycin for treatment of carbapenem-resistant Acinetobacter baumannii infections: A preliminary study. Antimicrob Agents Chemother 2014;58(9):5598-5601

151 Shields RK, Clancy CJ, Gillis LM, et al. Epidemiology, clinical characteristics and outcomes of extensively drug-resistant Acinetobacter baumannii infections among solid organ transplant recipients. PLoS ONE 2012;7(12):e52349

152 López-Cortés LE, Cisneros JM, Fernández-Cuenca F, et al. Monotherapy versus combination therapy for sepsis due to multidrugresistant Acinetobacter baumannii: analysis of a multicenter prospective cohort. J Antimicrob Chemother 2014;69(11): 3119-26

153 Niu C, Clemmer KM, Bonomo RA, Rather PN. Isolation and characterization of an autoinducer synthase from Acinetobacter baumannii. J Bacteriol 2008;190(9):3386-3392

154 Loehfelm TW, Luke NR, Campagnari AA. Identification and characterization of an Acinetobacter baumannii biofilm-associated protein. J Bacteriol 2008;190(3):1036-1044

155 Brossard KA, Campagnari AA. The Acinetobacter baumannii biofilm-associated protein plays a role in adherence to human epithelial cells. Infect Immun 2012;80(1):228-233

156 Tomaras AP, Flagler MJ, Dorsey CW, Gaddy JA, Actis LA. Characterization of a two-component regulatory system from Acinetobacter baumannii that controls biofilm formation and cellular morphology. Microbiology 2008;154(Pt 11):3398-3409

157 Tomaras AP, Dorsey CW, Edelmann RE, Actis LA. Attachment to and biofilm formation on abiotic surfaces by Acinetobacter baumannii: involvement of a novel chaperone-usher pili assembly system. Microbiology 2003;149(Pt 12):3473-3484

158 Choi AH, Slamti L, Avci FY, Pier GB, Maira-Litrán T. The pgaABCD locus of Acinetobacter baumannii encodes the production of poly$\beta-1-6-N$-acetylglucosamine, which is critical for biofilm formation. J Bacteriol 2009;191(19):5953-5963

159 Lees-Miller RG, Iwashkiw JA, Scott NE, et al. A common pathway for $O$-linked protein-glycosylation and synthesis of capsule in Acinetobacter baumannii. Mol Microbiol 2013;89(5):816-830

160 Iwashkiw JA, Seper A, Weber BS, et al. Identification of a general $O$-linked protein glycosylation system in Acinetobacter baumannii and its role in virulence and biofilm formation. PLoS Pathog 2012;8(6):e1002758

161 Tada T, Miyoshi-Akiyama T, Kato Y, et al. Emergence of 16S rRNA methylase-producing Acinetobacter baumannii and Pseudomonas aeruginosa isolates in hospitals in Vietnam. BMC Infect Dis 2013; 13:251

162 Taitt CR, Leski TA, Stockelman MG, et al. Antimicrobial resistance determinants in Acinetobacter baumannii isolates taken from military treatment facilities. Antimicrob Agents Chemother 2014;58(2):767-781 